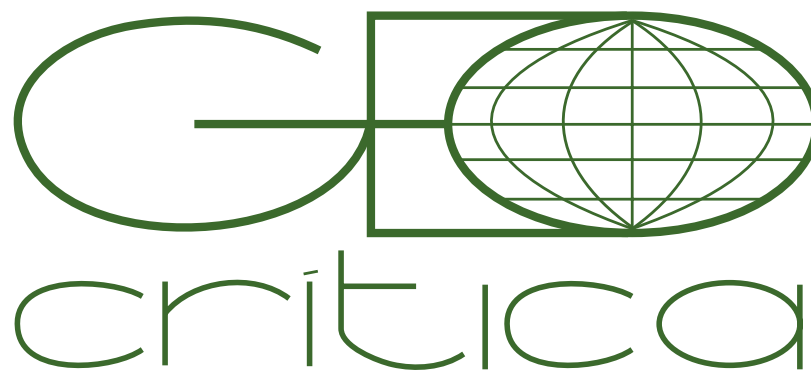

\section{Scripta Nova}

Revista Electrónica de Geografía y Ciencias Sociales Universitat de Barcelona

1 de febrero de 2018

\title{
EL NEGOCIO DE LA CONSERVACION AMBIENTAL: CÓMO LA NATURALEZA SE HA CONVERTIDO EN UNA NUEVA ESTRATEGIA DE ACUMULACIÓN CAPITALISTA EN LA ZONA ANDINO-LACUSTRE DE LOS RÍOS, SUR DE CHILE.
}

\author{
Luis Fernando De Matheus e Silva \\ luis.dematheus@ufrontera.cl \\ Hugo Marcelo Zunino \\ hugo.zunino@ufrontera.cl \\ Viviana Huiliñir Curío \\ viviana.huilinir@ufrontera.cl \\ Universidad de la Frontera
}

Recibido 10 de mayo de 2017. Devuelto para correcciones 24 de julio de 2017. Aceptado 29 de septiembre de 2017

El negocio de la conservación ambiental: cómo la naturaleza se ha convertido en una nueva estrategia de acumulación capitalista en la zona andino-lacustre de Los Ríos, sur de Chile (Resumen)

Actualmente, la "naturaleza" ha sido foco de una nueva estrategia de acumulación capitalista, y en determinados lugares se experimenta un proceso de resignificación, aprovechando características ecológicas y paisajísticas singulares. Es el caso de la zona andino-lacustre de la región de Los Ríos, sur de Chile. A fines del siglo XIX, este lugar fue incorporado a la economía nacional por medio de la explotación maderera-forestal. No obstante, a partir de la década de 1990, en función de las condicionas generadas por el actual momento histórico, la zona se ha convertido en una nueva frontera para la expansión capitalista, sustentada por la ideología de la naturaleza "prístina".

Palabras clave: neoliberalismo; conservación ambiental; privatización de la naturaleza.

Artículo elaborado gracias al apoyo del proyecto postdoctorado FONDECYT 2017 no 3170103.

"El negocio de lo prístino: Las consecuencias socioespaciales de la comodificación de la naturaleza y del paisaje en la zona lacustre-andina de Los Ríos"
The business of environmental conservation: how nature has become a new strategy of capitalist accumulation in the Andean lake area of Los Ríos, in southern Chile (Abstract)

Today, "nature" has turned into the target of a new strategy of capitalistic accumulation and in many locations the meaning that ascribed to places has shifted, taken advantages of unique ecological and landscape characteristics. This is the case of the Andean lake region of Los Ríos, in southern Chile. At the end of the 19th century, this place was joined to the national economy by means of the forestry industry. Nevertheless, from the decade of 1990, depending on the conditions generated by the current historical moment, the area has become a new frontier of capitalist expansion sustained by the ideology of "pristine" nature. Key words: neoliberalism, environmental conservation, privatization of nature 
A partir de la década de 1990, determinados lugares considerados importantes en biodiversidad y estéticamente atractivos, experimentaron un proceso de profunda transformación en función de la apreciación de sus atributos ecológicos y paisajísticos. La comodificación de la naturaleza y del paisaje ha ayudado a resignificar el medio rural en la actualidad, sirviendo como palanca para la territorialización de nuevas dinámicas y actividades en su interior. Este proceso debe ser comprendido históricamente, de acuerdo con las necesidades de la acumulación capitalista contemporánea, y a la luz de la urbanización de la sociedad.

Así, para dar cuenta de los motivos que hicieron de la naturaleza (conservada, y/o preservada) 1 una mercancía, y analizar las consecuencias socioespaciales producidas en las últimas tres décadas por la territorialización de los discursos y de las practicas conservacionistas ligadas al mercado, consideramos de la mayor importancia poner atención en el movimiento de la acumulación capitalista, especialmente en lo que se refiere a la voracidad del capital por encontrar nuevos valores de uso sociales que mercantilizar. En este sentido, partimos del supuesto que:

La acumulación es el motor que mueve el crecimiento bajo el modo de producción capitalista. El sistema capitalista es, por consiguiente, fuertemente dinámico y expansivo; forma una fuerza permanentemente revolucionaria que de manera continúa y constante remodela el mundo que vivimos².

Tomando la interpretación geográfica de la obra de Marx realizada por David Harvey, especialmente en los libros Los Limites del capitalismo (1990), El Nuevo Imperialismo (2004), y La producción capitalista del espacio (2009), entendemos que el carácter contradictorio del capitalismo -impulsado por la máxima de "acumular por acumular, producir por producir"- tiende siempre a generar crisis de sobreacumulación, es decir, situaciones en que su dinámica expansionista choca con un exceso de capital en relación con las posibilidades de poder emplearlo. No obstante, como sugiere el geógrafo británico, antes de llevar al fin del sistema, estas crisis han servido (al menos hasta ahora) como instrumentos de corrección periódicas forzosas en el curso de acumulación, cuyo papel es el de ampliar la capacidad productiva y renovar las condiciones para seguir con su movimiento. Entre las diversas formas encontradas por el capital para superar sus contradicciones internas y poder llegar a un plan superior, Harvey señala, entre otras, la constante necesidad de: 1) penetrar en nuevas esferas de actividad; 2) crear nuevos deseos y necesidades sociales; y 3 ) expandirse geográficamente ${ }^{3}$.

\footnotetext{
1 El debate entre preservacionismo y conservacionismo está en el origen del ambientalismo occidental y moderno. Ambos parten de una visión dicotómica para entender la relación entre sociedad y naturaleza. De un modo general, el primer término suele vincularse al establecimiento de espacios naturales "vírgenes" apartados del ser humano, mientras que el segundo se vincula a la preocupación con el medio ambiente y a las estrategias de desarrollo económico vigentes. En esta ocasión, preferimos utilizar el término conservacionismo, dado que las reservas de protección ambiental ligadas al mundo empresarial se orientan por la lógica del mercado.

2 Harvey, 2009, p.256.

3 Harvey, 2009.
} 
Desde los años 1970 el capital viene experimentando una grave e incontenible crisis de sobreacumulación4. Bajo este contexto crítico, la naturaleza -cada vez más privatizada y explotada como recurso- pasa a ser apropiada también como ideología, sirviendo para dotar al espacio de nuevos valores de uso y facilitar el funcionamiento del proceso de acumulación ${ }^{5}$. La incorporación a la dinámica capitalista del discurso y de determinadas prácticas conservacionistas se tornó aún más evidente durante la década de 1990, junto con la globalización y flexibilización del capitalismo. Esto, especialmente después de la Cumbre de la Tierra de Rio de Janeiro, ocurrida en 1992 (ECO 92), cuando las discusiones en torno a la ecología y a la conservación del medio ambiente pasaron a recibir cada vez más atención, siendo absorbidas por el status quo y convertidas en nuevas estrategias de acumulación capitalista, por medio de conceptos como "desarrollo sostenible". Como señala Cindy Katz (1998): "En menos de dos décadas, el capitalismo corporativo revirtió su oposición a los movimientos ecologistas, pasando a utilizar como suyos, diversos lemas del ambientalismo. En el curso de este proceso -y en el centro de él- la naturaleza se convirtió en una estrategia de acumulación de capital"7.

En este sentido, las críticas, que originalmente se destinaban al tipo de desarrollo impuesto al mundo en los últimos siglos (y llevadas al extremo en las últimas cuatro décadas), fueron redefinidas de modo de aportar a la reproducción de este sistema, que ahora se ve travestido de "ecológicamente y socialmente responsable". Dentro de este escenario, la cuestión ambiental muchas veces se ha reducido:

a un debate con fuertes connotaciones esquizofrénicas, en lo cual la gravedad de los riesgos con los cuales el planeta se encuentra (...) contrasta con las pifias y tímidas propuestas del tipo "plante un árbol", "promueva la colecta selectiva de la basura" o "desarrolle el ecoturismo"8.

Asimismo, para entender mejor los motivos de este proceso, no se puede perder de vista que el actual momento histórico, ubicado en el ápice del movimiento de implosión-explosión de las ciudades9, es marcado por una profunda crisis urbana, que es experimentada en escala global (aunque distribuida de forma geográficamente desigual). Dentro del mundo básicamente urbano moldeado a lo largo de la globalización del orden neoliberal, los problemas socioambientales se intensifican y los

4 Harvey, 2004.

5 De Matheus E Silva, 2013.

6 La apropiación del discurso conservacionista por el establishment se inicia a mediados de los años 1970, con la publicación del Informe Meadows (o "Los límites al crecimiento"), encargado al MIT por el Club de Roma. Asimismo, conforman parte estratégica fundamental del ajuste funcional de la cuestión ambiental a las necesidades del capital, las grandes reuniones globales sobre el medio ambiente, tales como la "Primera Conferencia Mundial sobre el Hombre y el Medio Ambiente", organizada por la ONU y realizada en Estocolmo en 1972, la "Conferencia de las Naciones Unidas para el Medio Ambiente y el Desarrollo" (o "Eco 92"), (COP3) que tuvo lugar en Kioto, Japón, así como las políticas derivadas de ellas (de Matheus e Silva, 2013).

7 Katz, 1998, p.46.

8 Porto Gonçalves, 2006, p.16.

9 Lefebvre, 2004. 
niveles de calidad de vida reducen sin parar. Así, nuevas "singularidades" 10 - como el aire limpio, el verde, el agua y el tiempo libre- son creadas, para posteriormente ser convertidas en mercancías. Esto ha llevado a una creciente valoración de las áreas "más naturales", que ganan nuevos significados y pasan a tener existencia real por medio de su intercambialidad, a través de la acción de los agentes inmobiliarios que utilizan el espacio como medio volcado hacia la reproducción ${ }^{11}$.

Es en medio a este contradictorio escenario de resignificación del medio rural, promovido por la urbanización y por las necesidades de la acumulación, que la naturaleza y el paisaje son espectacularizados, convirtiéndose en presupuestos para la nueva etapa de la reproducción capitalista en el campo. Con esto, verificamos en los últimos veinte años la territorialización de prácticas y actividades económicas que tienen en la "naturaleza" y en la "sustentabilidad" su leitmotiv, materializadas en la forma de parques y reservas biológicas privadas, sumados a complejos turísticos y emprendimientos inmobiliarios como condominios cerrados y parcelas de agrado. Todo esto aludiendo a la singularidad, a la "pristinidad", al bucolismo y a la belleza de ciertos parajes.

En Chile, este fenómeno, que Núñez, Aliste y Bello llaman de "mercantilización de la naturaleza como práctica espacial" ha adquirido cuerpo a fines de la década de 1990, siendo particularmente fuerte en las regiones más australes del país, donde:

el discurso de la conservación y la protección de la naturaleza se visualiza como un renovado mecanismo de colonización de aquellos territorios australes, sustentado en una capitalización de la naturaleza donde el valor 'ambiental' sustenta una nueva racionalidad económica en tanto objeto de transacción ${ }^{12}$.

Como parte del esfuerzo por entender la enmarañada trama geográfica que está siendo tejida en el medio rural del sur chileno en la contemporaneidad, con la incorporación del discurso y de las prácticas conservacionistas a las diferentes estrategias de la acumulación capitalista, en el presente artículo discutimos una de las aristas más complejas de este proceso: el establecimiento de las reservas de conservación privadas ligadas al mundo empresarial. Para esto, utilizamos como referencia empírica la reserva de conservación privada Huilo Huilo, ubicada en la zona lacustre-andina de la región de Los Ríos, más precisamente en la localidad de Neltume, comuna de Panguipulli.

Para desarrollar el argumento y poder abordar satisfactoriamente las cuestiones suscitadas en esta instancia, nos orientamos por una lectura teórica realizada a través de los lentes del "materialismo histórico-geográfico", valiéndonos de teorías y conceptualizaciones desarrollados por autores como David Harvey, Neil Smith, Cindy Katz, entre otros. Asimismo, incorporamos ciertos trabajos que desde diferentes perspectivas teórico-metodológicas, vienen buscado aprehender las transformaciones sociales, políticas, culturales y económicas experimentadas en Chile a lo

10 "Raridade", en portugués.

11 Alessandri Carlos, 2001.

12 Núñez; Aliste; Bello, 2014a., p.02. 
largo del proceso de neoliberalización del país. Paralelamente, analizamos con base en un enfoque crítico interpretativo, las informaciones contenidas en los archivos digitales, en las páginas web, y en las entrevistas y reportajes sobre Huilo Huilo y Neltume. Finalmente, nuestras discusiones son alimentadas por observaciones y por los datos levantados in situ, a través de la realización de los trabajos de campo en la zona durante 2016 y 2017. Se trata de un artículo exploratorio que sintetiza algunos de los primeros avances de una investigación más amplia, en la cual estudiamos los principales impactos socioespaciales engendrados por el proceso de comodificación de la naturaleza y del paisaje en la zona andino-lacustre de la región de Los Ríos, en sur de Chile.

El texto está dividido en tres partes. La primera es una breve contextualización histórica de la privatización y la comodificación de la conservación ambiental en Chile. Después de esta panorámica general, enfocamos nuestra mirada en la zona andino-lacustre de la región de los Ríos, donde presentamos, de modo puntual, ciertos hitos de la geografía histórica contemporánea de la zona, señalando los diferentes momentos de la producción capitalista de aquel espacio, desde su incorporación a la economía nacional por medio de la explotación maderera y forestal, hasta su transformación en una nueva frente de expansión capitalista, ahora sustentada por el discurso y por las prácticas conservacionistas. La incorporación del ambientalismo por el capital se analiza con mayor profundidad en la última parte, cuando nos centramos en la reserva Huilo Huilo. A partir de este estudio de caso, buscamos iluminar sobre cómo viene operando la comodificación de la conservación ambiental en la zona andino-lacustre de Los Ríos, e indicar algunas de las principales consecuencias generadas por este proceso en una escala local. Desde ya destacamos el acaparamiento de las tierras, la privatización y la espectacularización de la naturaleza, y aquello que entendemos como la monopolización del lugar.

\section{La privatización y la comodificación de la conservación ambiental en Chile.}

De un modo general, en Chile, la creación de parques y reservas naturales se ha constituido desde principios del siglo XX en la principal forma encontrada para proteger los espacios con atributos ecológicos importantes, y a la vez amenazados ${ }^{13}$. La primera área de protección ambiental establecida fue la Reserva Nacional de MalleCo, creada en 1907, después de la presión ejercida por naturistas preocupados con la perdida de los paisajes y de la biodiversidad de la zona cordillerana de la Araucanía,

13 Es importante mencionar que, de un modo general, la concepción de esas áreas protegidas tiene origen a fines del siglo XIX en Europa y en los Estados Unidos, y expresa una forma de relación sociedad-naturaleza típicamente moderna, occidental y urbana, que parte del principio de que la mejor forma de preservar la naturaleza es manteniéndola "separada" de la humanidad. Con base en esta concepción especifica de la relación sociedad-naturaleza, se han ido constituyendo "islas de pristinidad", en las cuales el hombre puede huir de su vida agitada y estresada para admirar y reverenciar la belleza y la magnitud de la "naturaleza salvaje" (Diegues, 1994). 
como consecuencia del incremento de la actividad agrícola, forestal y ganadera ${ }^{14}$. Entre 1958 y 1974, 61 "unidades de conservación", entre parques y reservas terrestres, fueron creadas al alero del Ministerio de Agricultura ${ }^{15}$.

A partir de la década de 1970, esta estrategia de conservación gana fuerza y el Estado chileno pasa a actuar más firmemente, decretando la creación de una serie de parques y reservas, sobre todo "en las regiones más extremas del país, donde una menor densidad poblacional y valores más bajos de las tierra hacia más fácil declarar grandes extensiones como áreas protegidas"16. Otro paso importante para la consolidación de las reservas de conservación ambiental en el país, fue la creación en 1984 del Sistema Nacional de Áreas Protegidas (SNASPE), ligado a la Corporación Nacional Forestal (CONAF) ${ }^{17}$. "El sistema siguió el marco de la Unión Internacional para la Conservación de la Naturaleza (IUCN) en la clasificación de las áreas de protección, donde cuatro categorías de conservación fueron establecidas: reservas vírgenes, parques nacionales, monumentos nacionales y reservas naturales"18.

Considerado hoy como uno de los más extensos sistemas de manejo de áreas protegidas de América Latina, el SNASPE "cumple con funciones clave como la protección de cuencas, el mantenimiento de la biodiversidad y la creación de espacios para el esparcimiento y el turismo"19. No obstante, aunque sea cierto que estas áreas protegidas cumplen con importantes funciones, no se puede ignorar que su conformación tiende a generar una serie de problemas de carácter político, social y económico, no siendo, por lo tanto, una simple cuestión de mantener el "mundo natural" y proteger la biodiversidad, como pretenden los preservacionistas más puristas ${ }^{20}$. En este sentido, Tecklin y Catalán (1995) dejan claro que el establecimiento de las reservas, parques y santuarios naturales bajo supervisión del SNASPE, no ha llevado en consideración las necesidades de las comunidades locales aldeanas, y su contribución a la mejoría de la calidad de vida de estas poblaciones hasta el momento ha sido escasa.

Acompañando los cambios generados a mediados de la década de 1990, cuando el ambientalismo pasa a asumir cada vez más centralidad en las agendas gubernamentales, el establecimiento de áreas de conservación ambiental en Chile entra en un nuevo momento, especialmente después que el país firma y ratifica el "Convenio sobre la Diversidad Biológica", acordado en la ciudad de Rio de Janeiro en 1992, durante la "Cumbre de La Tierra". Entonces, es promulgada la Ley sobre Bases Generales del Medio Ambiente y son definidos los conceptos de Conservación del Patrimonio Ambiental y las Áreas bajo Protección Oficial. Bajo nuevos criterios de

14 Pauchard; Villarroel, 2002.

15 MMA Chile, 2011

16 Rivera, Vallejos-Romero, 2015, p.17

17 La Corporación Nacional Forestal (CONAF) es una entidad de derecho privado dependiente del Ministerio de Agricultura. Su principal tarea es administrar la política forestal de Chile y fomentar el desarrollo del sector.

18 Rivera, Vallejos-Romero, 2015.

19 Tecklin; Catalán, 2005, p. 20.

20 Diegues, 1994. 
clasificación, la conservación del patrimonio ambiental pasa a ser considerada una categoría más amplia de protección, contemplando no solo los componentes biológicos del medio ambiente, sino que también los elementos culturales. Además de esto, y muy importante, "el país ha impulsado proyectos financiados internacionalmente, para abordar los desafíos de la conservación in situ y paralelamente han surgido iniciativas y propuestas de conservación privada" 21 .

Este último punto refleja una tendencia mundial que pasa a ser inaugurada en este momento: debido a la complejización de los problemas ambientales, y también de las condiciones producidas por la dinámica del capitalismo, la tarea de conservar los atributos naturales y paisajísticos deja de ser exclusividad del Estado, trasladándose cada vez más hacia la iniciativa privada. En Chile, la tercerización de la conservación gana fuerza en los últimos veinte años, siendo que actualmente existen más de 300 iniciativas privadas de conservación cubriendo aproximadamente 1,6 millones de hectáreas, según datos de $2013^{22}$.

La mayoría de estas áreas protegidas privadas son pequeñas (menos de 1.000 hectáreas). Sin embargo, 10 grandes áreas protegidas privadas cubren más de un millón de hectáreas (Mesa, 2009), representando más del $60 \%$ del total de superficie administrada por iniciativas privadas. Una pequeña fracción de estas iniciativas posee algún reconocimiento oficial, ya sea como santuarios de la naturaleza, sitios de turismo o zonas de caza23.

En un principio, este proceso fue capitaneado por empresarios-filántropos como Douglas Thompkins ${ }^{24}$, y por grandes ONGS ambientalistas transnacionales ${ }^{25}$, como The Wildlife Conservation Society (TNC), y World Wild Foundation (WWF). Estos actores, provenientes en su mayoría de los países capitalistas desarrollados del hemisferio norte, además de apropiarse de considerables porciones de tierra y de los recursos naturales existentes en el país, pasaron a ejercer gran influencia en las discusiones acerca de las políticas públicas nacionales respecto al "desarrollo sustentable". Y ya que estas ONGS y los grandes filántropos son en su enorme mayoría representantes legítimos de la clase capitalista, su visión del conservacionismo, además de dualista, es fuertemente influenciada por la retorica y por los principios liberales, como el de la propiedad privada.

21 MMA Chile, 2011, P.05-06

22 Rivera, Vallejos-Romero, 2015, p.18

23 Ibid.

24 Douglas Thompkins es considerado el pionero de la conservación privada en Chile. Este millonario estadounidense, practicante de montañismo y adepto de la "ecología profunda", adquirió los primeros terrenos para la conservación ambiental en la Patagonia chilena en principio de la década de 1990. Posteriormente, a través de la fundación "The Conservation Land Trust" fue comprando más terrenos, acumulando más de 280 mil hectáreas para la creación del Parque Pumalín, que se convirtió en el mayor parque privado del país. Con la muerte de Thompkins, en 2016, el Parque fue donado al Estado chileno, así como otras áreas protegidas que pertenecían al estadounidense.

25 No se puede ignorar el hecho de que esas ONGS mantienen estrechos vínculos con las grandes corporaciones. Por este motivo, son consideradas por muchos autores, entre ellos Harvey, como parte de los tentáculos más invisibles del capitalismo en su etapa neoliberal. 
De esto, resulta la creación de una economía capitalista "ecológicamente responsable", en la cual:

Las estrategias del desarrollo sustentable van a diseñar instrumentos capaces de llevar las prácticas propias del modelo neoliberal a utilizar nuevas herramientas en donde lo ambiental será el centro de atención, un elemento de los discursos y el mecanismo que permitirá mantener su estatus hegemónico ${ }^{26}$.

En ese sentido, necesitamos tener en consideración otro aspecto de la privatización de la conservación ambiental, que es justamente su transformación en una nueva estrategia de acumulación capitalista. En Chile, bajo un contexto en el cual el proyecto neoliberal nacional gana madurez, fueron creadas las condiciones políticas, económicas y sociales para que a fines de la década de 1990 inicio de los años 2000, emerjan reservas de conservación ambiental de carácter "privado-mercantil", pertenecientes a capitalistas y a grupos empresariales, nacionales y extranjeros. De un modo general, estos proyectos han atribuido valor de cambio a la naturaleza, uniendo el ambientalismo con el discurso y las prácticas capitalistas.

Conforme mencionamos anteriormente, la comodificación de la conservación ambiental está bastante presente en las regiones más australes del país. Para ello, la geografía ha jugado un rol fundamental, pues si por un lado las características naturales de estas regiones de cierta forma imponen límites a la expansión de la frontera agrícola nacional ${ }^{27}$, por otro, generan condiciones ideales para la extracción de renta de la tierra a través de otros medios, como es el caso de la conservación ambiental. Los bajos valores comerciales de los terrenos hasta mediados de los años 1990, las facilidades para adquirirlos, sumado a los incentivos fiscales y a las nuevas posibilidades de generar renta por medio de la naturaleza conservada, han motivado la inversión en tierras por parte de esos "neo-ecologistas". Así, presenciamos una nueva etapa de la expansión de la frontera capitalista en medio rural de sur de Chile $^{28}$, ahora justificada por los propósitos de la protección de ecosistemas frágiles y paisajes únicos.

Ahora bien, si la creación de áreas de protección ambiental ocurrida bajo la responsabilidad del Estado ya es de por sí algo problemático, cuando se transfiere esta tarea a manos privadas, circunscribiéndola a los límites del libre-mercado, la tendencia es a que se incremente y complejicen aún más los problemas sociales. Esto porque, sobrepuesta a la visión occidental y moderna de la relación sociedad-naturaleza, aparece una mirada funcional-mercantil del conservacionismo, que busca proteger a la naturaleza en función de las ganancias que ella puede generar. En este sentido, la comodificación de la conservación -al traer consigo las contradicciones

26 Núñez; Aliste; Bello, 2014a., p.07.

27 Echenique, 2012.

28 De acuerdo con nuestra perspectiva teórica, los movimientos de frontera actúan tanto "externamente", en dirección a la absorción de nuevos territorios y configuraciones socioespaciales hasta entonces situados "al margen" de la lógica del capital, como "internamente", a través del incremento y de la constante re-creación de las relaciones capitalistas de producción al interior de lugares ya insertos en la dinámica de la acumulación. 
propias de una sociedad de clases- ha contribuido para problematizar aún más la ya conflictiva dinámica socioespacial presente en el medio rural chileno contemporáneo, actuando como un importante componente para la resignificación de determinados lugares que son plenos de diversidad, simbología y de recursos, con una serie de impactos que afectan a las "comunidades locales"29.

\section{La conservación ambiental como palanca para la producción capitalista del espacio en la zona andino-lacustre de Los Ríos en el actual momento histórico.}

Uno de esos lugares privilegiados para la nueva etapa del desarrollo capitalista vía la conservación ambiental en el medio rural, es justamente la zona andino-lacustre de la región de Los Ríos. Dicha zona viene llamando la atención en virtud de su potencial ecológico y paisajístico, atrayendo diversos sujetos sociales preocupados en proteger la riqueza ecológica del bosque templado lluvioso valdiviano, y sus paisajes "prístinos", de verdes bosques, volcanes nevados, ríos, cascadas y lagos de agua cristalina.

Es importante dejar claro que la conservación del bosque templado lluvioso valdiviano -que posee una gran variedad de especies y géneros endémicos, y una de las más altas biomasas conocidas para un ecosistema terrestre ${ }^{30}$, es una labor urgente y necesaria, sobre todo si tomamos en consideración que este ecosistema está sometido a una presión cada vez mas intensa debido a la expansión urbana, al avance de los monocultivos forestales y al incremento de los proyectos de generación hidroeléctrica, elementos todos necesarios a la mantención del modelo de crecimiento económico adoptado por el país. No obstante, el modo dominante por el cual se pretende mantener protegido aquel ecosistema, reproducido bajo la óptica liberal, viene generando cuestiones que merecen ser estudiadas con más cuidado, específicamente en lo que se refiere a los cambios en la tenencia de la tierra, a la apropiación privada de los bienes comunes, y a la construcción y la reproducción de un discurso que legitima todo esto. Así, entendemos que defender a "la naturaleza" es tan importante como discutir la manera por la cual esta tarea debe ser realizada.

Sin embargo, antes de poder continuar con esta discusión, precisamos volver por un breve instante a la geografía histórica contemporánea de la zona, señalando ciertos momentos que han marcado la producción capitalista de aquel espacio. De ese modo, queda más fácil percibir el movimiento -dirigido por el Estado y por el capital que ha transformado en un "santuario ecológico" y en un importante destino

29 Cindy Katz llama la atención sobre el cuidado que se debe tener con el uso de términos generalizadores como el de "comunidades locales". Según la geógrafa, "Las poblaciones residentes en zonas de conservación o de preservación ambiental son vistas de modo homogéneo, siendo descritas como "gente local" ("local people") por quienes presumiblemente se ven a sí mismos como 'trans-locales' y, por lo tanto, más importantes. Como todas las estrategias de "otredad", la creación de la "gente local" tanto romantiza, como permite excluir, explotar y marginar a esas poblaciones" (Karz, 1998, p.55).

30 Tecklin; Catalán, 2005 
turístico, un lugar que conformaba el territorio ancestral de diversas comunidades de origen Mapuche ${ }^{31}$, y que después, con el avance y la consolidación del Estado chileno a fines del siglo XIX, pasó a estar integrado a la economía nacional por medio de la explotación maderera y forestal ${ }^{32}$.

Durante casi todo el siglo XX, la actividad forestal y maderera fue el motor que impulsó el desarrollo socioeconómico de la zona, estimulando la fundación de poblados y ciudades, la construcción y/o la mejoría de las vías de circulación (lacustres y viales, primero, ferroviarias después), y el establecimiento de trabajadores provenientes de otros lugares ${ }^{33}$. Asimismo, el crecimiento de la industria maderera y forestal vino acompañado de una serie de conflictos, relacionados en gran medida con la explotación de la mano de obra, con la talla excesiva de los bosques, con el despojo de las comunidades indígenas y con el acaparamiento de las tierras. Respecto a este aspecto específico, antes de la reforma agraria iniciada en fines de los años 1960, la estructura fundiaria de la zona era altamente concentrada, estando la tierra dominada por un número reducido de propietarios, en fondos que iban de 10 mil a 80 mil hectáreas. Al mismo tiempo, el territorio mapuche había sido reducido casi a quince por ciento de lo que era ${ }^{34}$.

Con la llegada de Salvador Allende al poder en 1970, y durante todo el gobierno de la Unidad Popular ${ }^{35}$, la zona pasa por un período de gran agitación, marcado por el fortalecimiento de sindicatos y organizaciones de trabajadores rurales e indígenas, y por la profundización de la reforma agraria. Uno de los casos más significativos de esta agitación tuvo lugar justamente en la comuna de Panguipulli, cuando en el año de 1970, 22 fundos fueron expropiados y posteriormente traspasados al recién creado Complejo Forestal y Maderero de Panguipulli, empresa estatal ligada a la Corporación de Fomento de la Producción (CORFO) ${ }^{36}$. De acuerdo con el Comité Memoria de Neltume, de todos los fundos expropiados, solo uno contaba con sus escrituras en día, "todos lo demás eran fraudes y usurpaciones a las comunidades

31 Según el informe de la Comisión Verdad Histórica y Nuevo Trato con los Pueblos Indígenas de 2008, la cuestión de denominación del pueblo mapuche es demasiado compleja, y es muy difícil captarla bajo la lógica moderna y occidental. Siguiendo la orientación del informe, en el presente estudio se optó por utilizar la expresión "mapuche" de forma genérica, ya que esta es la denominación más utilizada por sus propios descendientes.

32 El proceso que abrió las puertas a la expansión capitalista en la zona -enmarcado dentro de aquello que Karl Marx denomina como acumulación primitiva (u originaria)- ha sido caracterizado por la violencia, por engaños y despojos. Los testimonios históricos dan cuenta de esta dinámica: "Esos atropellos son denunciados por los mapuche en el "Parlamento de Coz Coz" de 1907, ante el padre Sigisfredo, autoridades y periodistas. El proceso de despojo es similar en Neltume, Liquiñe, Futrono, Lago Ranco y Llifén". Comité Memoria Neltume, 2013, p.30.

33 Skewes et al, 2011.

34 Comité Memoria Neltume, 2013.

35 La Unidad Popular (UP) era el nombre de la coalición de izquierda que asumió el poder del Estado chileno en 1970, con la elección de Salvador Allende como Presidente. El objetivo de la UP era instaurar el socialismo en Chile por la vía democrática.

36 La Corporación de Fomento de la Producción (CORFO) es una agencia del Estado chileno que fue fundada en 1939, con el objetivo de promover la industrialización del país. Vinculada al Ministerio de Economía, Fomento y Turismo, la labor de CORFO es apoyar el emprendimiento, la innovación y la competitividad del país 
mapuche" (p.32). Según este documento, en su momento de mayor actividad, el Complejo empleó a 3.600 trabajadores, y poseía 360 mil hectáreas desparramadas por casi toda la cordillera de la Provincia de Valdivia, incluyendo, entre otros, los fondos Neltume, Carranco, Huilo Huilo, Pilmaiquen, Arquihue, Mocho, Maihue, Pirihueico, Chan Chan, Enco y Toledo ${ }^{37}$.

Durante casi tres años, los trabajadores de cuatro comunas se sienten dueños de su destino. Todos opinan, crean, construyen, deciden, estudian, reforestan, aprenden, crecen. De pronto, tener una vida mejor era algo que estaba al alcance de la mano, de sus propias manos, y todos se dieron con alegría y esperanzas a la tarea de construir sus propios futuros. Fue una transformación radical, hermosa, de las vidas de las gentes de las montañas. ${ }^{38}$

Esta época es recordada por las comunidades locales como un tiempo de abundancia, una "época generosa". Pero la experiencia popular dura poco, y luego "después llegó el tiempo malo, que siempre viene del norte" ${ }^{\prime 39}$. Esta vez, el "mal tiempo" es anunciado por el bombardeo de la Moneda en 1973, y la consecuente instauración de la dictadura cívico-militar en el país. El gobierno dictatorial, orientado por la ortodoxia liberal y sustentado por la fuerza de las armas, promovió diversos cambios que ayudaran a crear las condiciones necesarias para que el capital se re-territorializase en el medio rural chileno ${ }^{40}$.

En la zona andino-lacustre de Los Ríos, la modernización y la racionalización de la explotación del bosque nativo, junto con la expansión de los monocultivos forestales y la producción de celulosa fueron vistas, en principio, como las principales estrategias para dinamizar el desarrollo capitalista en la zona. Esto en un contexto marcado por la imposición de una nueva regionalización del espacio económico nacional ${ }^{41}$, sustentada por la privatización de los bienes comunes y el desmantelamiento de empresas públicas, por la persecución y la violencia en contra de los trabajadores rurales, de los campesinos y, claro, de las comunidades indígenas, que se vieron completamente excluidas del "acceso a recursos básicos que le habían sido fundamentales para su existencia. El temor, el hambre y la supervivencia se imponen como forma de vida en los años que siguen" ${ }^{42}$.

En este sentido, es posible trazar un paralelo entre lo que ocurrió durante los años del shock neoliberal promovido por los militares (en asociación con sectores de la sociedad civil), con los mecanismos de acumulación primitiva, que posibili-

37 Alfaro Monsalve, 2016

38 Comité Memoria Neltume, 2013, p.32.

39 Ibid., p.33

40 de Matheus e Silva, 2016.

41 A partir del golpe de Estado de 1973, Chile abandona el modelo de "desarrollo hacia adentro" que dominaba hasta entonces, y pasa a depender cada vez más de la exportación de bienes primarios. Bajo las nuevas condiciones engendradas por la neoliberalización de la economía chilena, las regiones experimentaron un proceso de especialización productiva, en función de sus principales ventajas comparativas (de Matheus e Silva, 2016). En ese sentido, la mirada "funcionaltecnocrática-liberal" al territorio trató de buscar cuáles serían las actividades económicas que mejor se adaptarían a las condiciones geográficas específicas de cada región en particular.

42 Skewes et al, 2011, p.45. 
taron la apertura del camino hacia el desarrollo capitalista en la zona durante la segunda mitad del siglo XIX. Esta similitud, evidentemente, no es una coincidencia. Como bien explica David Harvey (2004), la geografía histórica del capitalismo viene siendo moldeada a través de una relación orgánica entre la reproducción expandida y los violentos mecanismos de desposesión. Estos últimos, enseña Harvey, son particularmente importantes en los momentos de crisis de sobreacumulación por los cuales pasa necesariamente el capitalismo, actuando en el sentido de liberar activos a costos muy bajos para que el capital sobreacumulado pueda apoderarse y dar a ellos un uso lucrativo. Por este motivo, en lugar de "acumulación primitiva", el geógrafo británico prefiere el término "acumulación por desposesión"43.

Es justamente en función de la grave crisis de sobreacumulación del capitalismo instaurada desde el principio de los años 1970, que debemos entender la aplicación de los mecanismos de acumulación por desposesión engendrados por la dictadura chilena, particularmente la contrarreforma agraria, la represión al trabajo organizado, el debilitamiento de las organizaciones sociales, la precarización laboral ${ }^{44}$, la parcelación de las tierras indígenas ${ }^{45}$, y la privatización de los bienes comunes y del patrimonio público. Estos mecanismos permitieron asentar las bases para la edificación de una nueva etapa del desarrollo capitalista en el medio rural chileno entre las décadas de 1970 y 1980, contribuyendo para que una nueva geografía fuese diseñada en la zona andino-lacustre de Los Ríos.

En consonancia con las enormes transformaciones económicas, políticas y sociales verificadas en escala mundial a fines del siglo XX, con la globalización del capitalismo en su etapa neoliberal, a partir de la década de 1990 -dentro de un contexto nacional marcado por el retorno a la democracia formal- la reconfiguración del medio rural de la zona entra en otra etapa, caracterizada sobre todo por la diversificación y flexibilización de los usos del suelo, y por la territorialización de nuevas actividades económicas. En este sentido, se verifica, por un lado, el incremento de los proyectos de generación hidroeléctrica, como la Central Neltume, de responsabilidad de la multinacional ENDESA-ENEL, y por otro, el establecimiento de reservas privadas de conservación ambiental, seguido por una serie de negocios vinculados al turismo, como posadas, hoteles, restaurantes, y emprendimientos inmobiliarios.

Estas nuevas actividades acabaron por complejizar la geografía producida en la zona, engendrando una dinámica socioespacial contradictoria, que no solo ha incrementado la competencia intercapitalista por apropiarse de la tierra y de la naturaleza, sino que también la disputa ideológica acerca del futuro de la zona cordillerana de sur de Chile. Por este motivo, Blanco Wells (2008) defiende la existencia de una

43 De Matheus e Silva, 2016.

44 Acerca de la precarización laboral producto de este proceso, Alfaro Monsalve (2016) llama la atención sobre el hecho de que en 1983 restaban a penas 241 trabajadores permanentes en los fondos del Complejo, contra los 3200 que existían en 1972.

45 A este respecto, es importante señalar que en 1979 la Ley 17.729 que protegía las tierras indígenas, fue modificada con el objetivo de "terminar con la discriminación de que han sido objeto los indígenas" y estimular el régimen de propiedad privada entre los pueblos originarios. 
"paradoja de doble patrimonialización" de la naturaleza en las regiones más australes del país, que contrapone una "vocación" mercantil-productiva del espacio por un lado y estetizante-ecologista por otro. Ahora bien, aunque es correcto diferenciar estas dos lógicas de apropiación de la tierra y de la naturaleza (y consecuentemente de las diferentes rentas generadas por ellas), consideramos que es importante hacer hincapié que la vocación "estética-ecologista" y la "productivista", no son necesariamente dicotómicas, sino que más bien un par dialéctico, obedeciendo a la lógica mercantil. Así, ambas deben ser entendidas como parte de las estrategias contradictorias para la expansión de la frontera capitalista al interior del espacio rural contemporáneo.

No obstante, a diferencia de las centrales hidroeléctricas, las reservas de conservación ambiental privadas y los negocios vinculados al turismo acaban por generar la simpatía de la población, gracias a la reproducción del discurso de sustentabilidad y de empleabilidad. Así, estos proyectos son percibidos no solo positivamente, sino que también como necesarios para la conservación de la naturaleza y para la reproducción social de las comunidades locales, quedando prácticamente libres de críticas. Pero, más allá de esta visión superficial que simplifica y reduce la realidad a un mero fetiche, lo cierto es que la territorialización de una práctica conservacionista orientada por la lógica del valor de cambio no está libre de contradicciones. Por el contrario, es particularmente conflictiva en lo que se refiere a las profundas transformaciones en la tenencia de la tierra, con la consecuente reconcentración fundiaria, el incremento de la especulación inmobiliaria, y la apropiación privada de los bienes comunes. En este sentido, la reserva de conservación privada Huilo Huilo constituye uno de los casos más reveladores de cómo se desarrolla el contradictorio proceso de conversión del conservacionismo ambiental en una nueva estrategia de acumulación capitalista en el medio rural del sur chileno.

\section{La territorialización del conservacionismo de mercado: el caso de Huilo Huilo.}

Vinculada al grupo económico Themcorp ${ }^{46}$, la reserva biológica Huilo Huilo empezó a ser formada en el comienzo de la década de 1990, y hoy es considerada una de las reservas naturales más importantes y conocidas de sur de Chile. Ubicada entre las localidades de Neltume y Puerto Fuy, comuna de Panguipulli, la reserva posee actualmente 100 mil hectáreas, siendo una de las mayores áreas de protección privada en el país. De este modo, lo primero que tenemos que reparar es la enorme cantidad de tierras concentrada en las manos del grupo empresarial para los fines de conservación, y lo poco que realmente se conoce acerca de cómo estos terrenos fueron adquiridos. En este sentido, podemos afirmar que la reserva configura un

46 El Grupo Themcorp es un holding que concentra verticalmente diversas empresas que actúan en las más variadas áreas, destacando el desarrollo de tecnologías, productos y servicios volcados hacia la minería, a la construcción civil, y a la agricultura (fertilizantes), soluciones de higiene (veterinaria, industrial y de consumo masivo), además de la explotación forestal y de los negocios inmobiliarios y turísticos. Es en este rubro que entra Huilo Huilo. 
renovado tipo de latifundio, ahora "verde", bastante representativo de la nueva etapa del proceso de territorialización del capital monopolista ${ }^{47}$ en el medio rural de la zona andino-lacustre de Los Ríos. Aquí, la renta de la tierra ya no proviene exclusivamente de la actividad forestal y maderera, como en otros tiempos históricos, sino que principalmente de los negocios de la conservación.

Moreira (1995) recuerda que en el sentido capitalista, la inmovilización de capital en tierras -productivas o improductivas- significa la territorialización del capital. No es algo extraño al capitalismo, sino que es propio de él. Tiene que ver con la territorialización de sus intereses, siendo la biodiversidad uno de ellos. Así, la categoría de renta de la tierra (coherente con la teoría del valor marxista) emerge como crucial para entender el proceso de acaparamiento de tierras vinculado a la comodificación de la naturaleza y del paisaje. La renta de la tierra se relaciona directamente con el valor de uso de la misma, y este cambia en función de las circunstancias históricas. En otros términos, la especificidad de la "mercancía tierra" frente a las demás mercancías es justamente el hecho de que su valor de cambio no está asociado a un sólo valor de uso ${ }^{48}$. Por esto, Marx afirma que la renta no nace del suelo, sino que es algo socialmente producido.

Analizando la geografía histórica de la zona andino-lacustre de Los Ríos en el lugar donde hoy se ubica Huilo Huilo, se puede colegir que la forma de extraer renta de la tierra viene sufriendo una mutación, dejando de ser apenas "absoluta" y "diferencial" ${ }^{49}$, para tornarse cada vez más "renta de monopolio". Este tipo de renta es aquella parte del lucro suplementar derivada del monopolio sobre una porción de la superficie terrestre, dotada de cualidades especiales, "únicas". Así, la renta de monopolio no depende del precio general de la producción, sino que del deseo social o de la capacidad de compra de los consumidores ${ }^{50}$. En un contexto de crisis ambiental y urbana, los paisajes estéticamente atractivos, la biodiversidad y el capital simbólico construido en torno al bosque templado lluvioso valdiviano, se convierten en estas preciosas -y raras- mercancías.

Ahora bien, no se puede perder de vista que las otras rentas no desaparecen, pero se ponen en relación con la renta de monopolio. Por ejemplo, la renta diferencial puede ganar nuevo estimulo en la medida que los bosques preservados son financierizados, siendo comercializados en los mercados de títulos de carbono, con base en su potencial de generación de biomasa. De la misma manera, la renta absoluta se potencia con la especulación inmobiliaria. Por lo tanto, dado que en una

47 Para el geógrafo brasileño Ariovaldo Umbelino de Oliveira (2007), el proceso de territorialización del capital monopolista en el campo está caracterizado, entre otras cosas, por el hecho de que el capitalista y el propietario de tierra pasan a ser una solo persona, y por el predominio de las relaciones específicamente capitalistas de producción.

48 Moreira, 1995.

49 La renta absoluta se origina con la propiedad privada de la tierra. En cambio, la renta diferencial se origina de la explotación capitalista de la tierra, dependiendo en el caso de la producción forestal, de la cantidad de madera generada por cada fracción del bosque, de la tecnología empleada y de las facilidades de transporte.

50 Oliveira, 2007. 
sociedad basada en la propiedad privada, la inmovilización del capital-dinero en forma de propiedad fundiaria representa la garantía de acceso privilegiado, o mismo el monopolio, sobre la(s) posible(s) renta(s) que pueden ser extraída(s), la inversión en tierra configura, la mayor parte de las veces, un excelente negocio. Con esto en mente, podemos ahora discutir cómo y cuando se dio el proceso de conformación del área que hoy pertenece a Huilo Huilo.

Por un lado, desde la llamada "Pacificación de la Araucanía", la propiedad privada de la tierra en lo que antes era territorio mapuche constituye una cuestión engorrosa, estando su historia marcada por la violencia, el robo y el fraude, lo que hace muy difícil seguir con precisión los sucesivos movimientos de compraventa. Por otro lado, los oscuros meandros de la contrarreforma agraria y de las privatizaciones llevadas a cabo en Chile durante los años 1970 y 1980, tornan esta tarea aún más complicada. Sin embargo, es justamente en los complejos mecanismos de desposesión engendrados por la neoliberalización de la economía chilena, que deben ser buscadas las raíces de la conformación de la reserva Huilo Huilo, particularmente después de la venta de los fondos originalmente controlados por el Complejo Forestal y Maderero de Panguipulli.

Este proceso tiene inicio en 1973, dentro de los marcos de la llamada "regularización de la Reforma Agraria" ${ }^{51}$. En esta primera instancia fueron vendidas 48.196 hectáreas y un total de 38 mil fueron devueltas a sus "antiguos propietarios". Asimismo, en 1974 fue firmado un acuerdo entre CORFO y la empresa japonesa $\mathrm{Ma}$ ruberi Corporation para la construcción de una planta de celulosa en Panguipulli ${ }^{52}$. Durante la segunda ola privatizadora por la cual pasó el país, entre 1985 y 1989, bajo el comando de Herman Büchi ${ }^{53}$, la privatización del Complejo se consolida completamente. En 1984 fue vendido en Fondo Trafún Sur, y en 1985 los fondos Toledo y Curalelfu. De esto resulta que, en 1985, solo restaban bajo control estatal 10 predios, con un total de 174 mil hectáreas ${ }^{54}$. En 1986, CORFO anuncia la venta de 88.915 hectáreas que aun permanecían bajo control del Complejo, incluyendo los predios Payahuinte, Molco, Huilo Huilo, Pilmaiquen, Pirihueico y Arquihue, que fueron licitados como una sola unidad, además de aquellos enajenados de forma individual,

51 La contrarreforma agraria, entre otras cosas, promovió la devolución de tierras a sus (otrora) "dueños", la venta de las parcelas de reforma agraria (incluyendo aquellas que fueron ejecutadas por las instituciones financieras debido al sobreendeudamiento de los campesinos), el remate de las tierras públicas, y la fragmentación de las comunidades indígenas (de Matheus e Silva, 2016).

52 Alfaro Monsalve, 2016.

53 Herman Büchi fue Ministro de la Hacienda durante el gobierno dictatorial, entre los años de 1985 y 1989, y se lanzó a la candidatura presidencial por el conglomerado político de derecha apoyado por Augusto Pinochet, en las primeras elecciones postdictatoriales del país. Después de la crisis que azotó a Chile en el comienzo de la década de 1980, el ex ministro Büchi busco asegurar el apoyo del empresariado y del FMI "mediante la venta de los activos del Estado que aún formaban parte del núcleo de la antigua estrategia desarrollista (...). De ese modo se cumpliría, por fin, el anhelo de las autoridades del régimen, que consistía en generar una poderosa clase empresarial capaz de conducir la economía chilena sin la participación del Estado" (GÁRATE CHATEAU, 2012, p.310).

54 Alfaro Monsalve, 2016. 
específicamente los fondos Neltume, Carranco, Enco, Riñinahue y Caulle. En 1987, la Compañía Forestal y Minera Panguipulli S.A. adquiere los fondos Pilmaiquen y Arquihue. Finalmente, en 1991, la Forestal Neltume Carranco S.A, empresa del grupo Themcorp, pasa a controlar la explotación forestal en la zona ${ }^{55}$.

La mayor parte de las 100 mil hectáreas controladas hoy por Huilo Huilo corresponde a estos fondos privatizados. Los demás terrenos fueron adquiridos de particulares, especialmente campesinos, indígenas y trabajadores rurales, que tenían el dominio sobre algunas tierras, pero que en aquel momento se encontraban en serias dificultades para reproducirse socialmente ${ }^{56}$, viéndose, así, obligados a vender sus lotes a precios muy bajos, y/o migrar para otros lugares en búsqueda de mejores condiciones de vida ${ }^{57}$. La figura 1 -que superpone el área de la reserva Huilo Huilo, con los principales fondos que conformaban parte del Complejo Forestal y Maderero Panguipulli- ayuda a entender mejor la dimensión del proceso de acaparamiento de la tierra en la zona andino-lacustre de Los Ríos, engendrado por la conformación de la reserva.

No obstante, la historia oficial de la reserva no solo trata de apagar el pasado de emancipación experimentado por los moradores de la zona durante el corto período del gobierno de la Unidad Popular, sino que además es completamente omisa en relación a la historia de violencia, represión y desposesión sufrida por los campesinos, indígenas y trabajadores rurales locales después del golpe de 1973. Obviamente, este "olvido" no se da sin razón, y puede ser leído como un recurso ideológico que no solo despista sobre los procesos y mecanismos que permitieron conformar la reserva, sino que también justifica y naturaliza su forma de actuar.

Para entender cómo opera la construcción del lugar basado en esta "ideología de la naturaleza prístina"58, el análisis del discurso reproducido por los folletos, las páginas web y los reportajes acerca de Huilo Huilo resulta esclarecedor. En este tipo de material, la reserva suele ser presentada como la principal responsable por cambiar una historia de "unos 80 años de intensivas explotaciones forestales en la pre-cordillera"59, al plantear una nueva manera de ver el bosque nativo que:

Reencantó a los mismos habitantes de Neltume, que se caracterizan por su acogedora recepción y capacidad de emprendimiento, logrando paulatinamente reconvertir esta zona típicamente maderera en un destino turístico sustentable y comprometido con la conservación de su hábitat.60

55 Ibid.

56 Un reflejo de este momento crítico experimentado en la zona es justamente la disminución de la población que vivía en aquellos predios, que, de 20 mil en 1972, pasaron a ser apenas 5000 a mediados de la década de 1980 (Ibíd.).

57 Aún faltan informaciones y datos más precisos que permitan detallar el proceso de conformación territorial de Huilo Huilo a partir de la compra de esos fondos. Dado su importancia y complejidad, este tema deberá ser trabajado de manera más profunda en otras ocasiones.

58 Smith, 2010.

59 Andrade, 2002.

60 Fuente: <http://www.huilohuilo.com.>[06 de abril de 2016] 


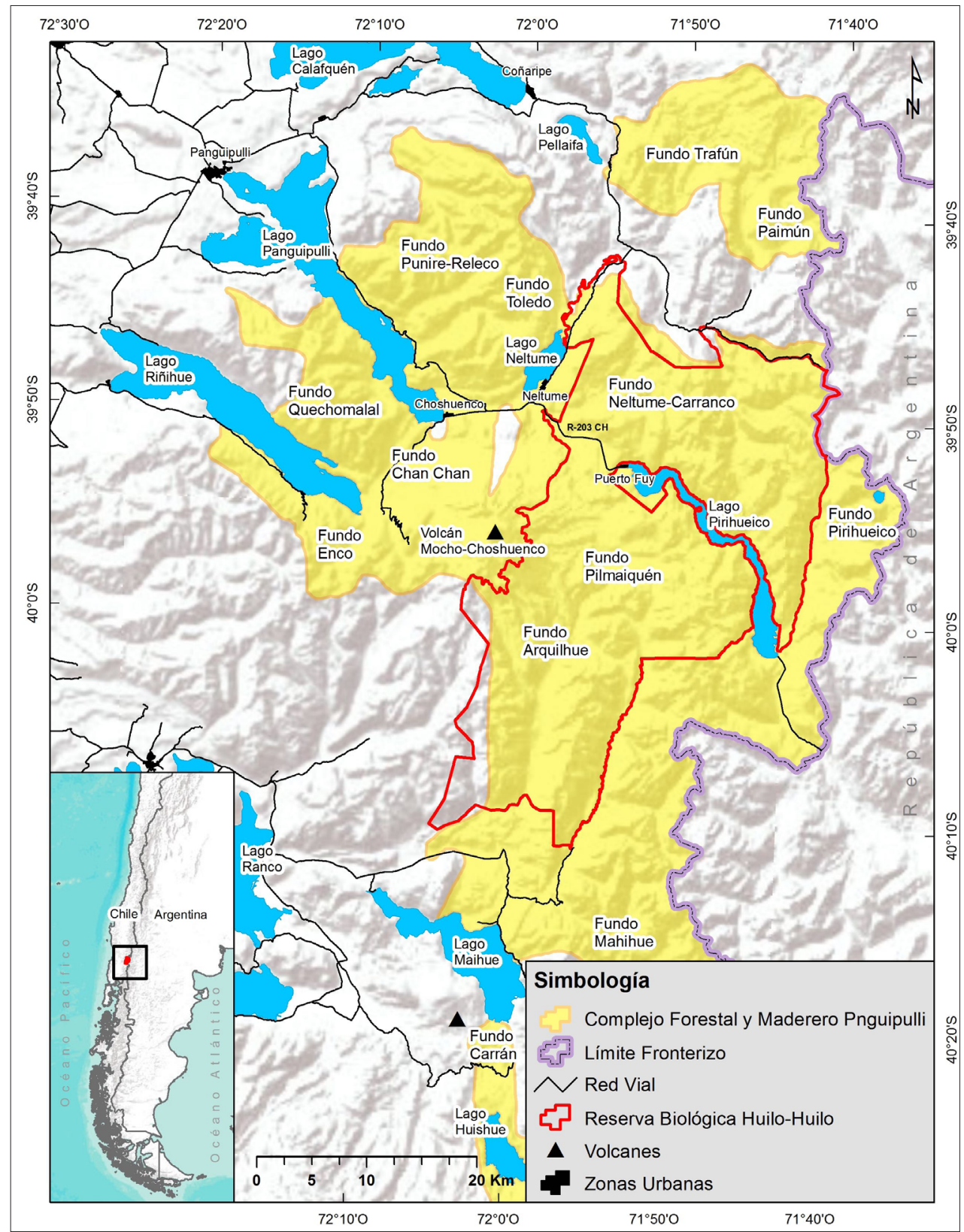

Figura 01: Superposición del área de Huilo Huilo con los principales fondos del antiguo Complejo Forestal y Maderero Panguipulli. En este mapa, es posible notar la dimensión de este nuevo "latifundio verde" surgido en la zona andino-lacustre de Los Ríos, a partir de la contrarreforma agraria y de la ola privatizadora que asoló el país durante los años 1970 y 1980

Fuente: Adaptado de: Barrena Ruiz; Hernando Arrese; Rosas Marchini, 2016.

De acuerdo con este tipo de discurso, la configuración de Huilo Huilo se justifica en función de su rol central en la conservación de "los encantos" y de la diversidad de un ecosistema que corría riesgo, debido a la superexplotación de sus recursos naturales por la actividad forestal-madera. Al mismo tiempo, gracias a la reserva, el lugar ha pasado por una profunda resignificación, transformándose en un "destino turístico sustentable", en el cual sus moradores pudieron encontrar trabajo y ejercitar su capacidad de emprendimiento. Así, como si fuese por obra mágica (tal vez 
de los gnomos y hadas que -como se suele afirmar- habitan los bosques de la reserva $)^{61}$, los conflictos desaparecen o quedan en el pasado, y en su lugar surge Huilo Huilo, para "salvar" la fauna y la flora del bosque templado lluvioso de la extinción, y garantizar a los habitantes de la zona mejores condiciones de trabajo y de vida. El "libre mercado" se reafirma, de ese modo, como el mecanismo más eficaz para ajustar los desequilibrios ecológicos y las desigualdades sociales ${ }^{62}$. Ahora bien, debemos cuestionar hasta qué punto esto corresponde a la realidad.

No cabe duda que Huilo Huilo ejerce actualmente un papel destacado en la conservación del bosque valdiviano y de los paisajes de la zona andino-lacustre de Los Ríos. Esto es cierto, si consideramos la enorme área que posee. Al mismo tiempo, es cierto también que la reserva estimula la investigación científica por medio de convenios con universidades y centros de investigación, además de promover acciones educacionales, filantrópicas y talleres profesionales junto a las comunidades vecinas a la reserva (destinadas especialmente a las mujeres) $)^{63}$, sin contar que es una importante fuente laboral para los habitantes de la zona ${ }^{64}$.

Pese a lo anterior, es interesante observar que, contradictoriamente, una parcela considerable de los problemas socioambientales verificados en la zona a partir de la década de 1980, tuvieron como protagonistas justamente los propietarios de Huilo Huilo. En este sentido, no se puede perder de vista que hasta las décadas de 1990, la principal actividad del grupo Themcorp en la zona residía en la explotación forestal y maderera, a través de las empresas Forestal Bosques y Maderas S.A. (BOMASA) y Forestal Neltume Carranco. Esta última, además de verse involucrada en diversos conflictos ambientales, también se tornó conocida por profundizar la precarización laboral y social de los trabajadores de la zona ${ }^{65}$.

Así, cabe indagar cuales fueron los verdaderos motivos que llevaron Themcorp a modificar su estrategia de acción en la zona. Algunos pueden argumentar que esto ocurrió en función de una toma de conciencia ambiental, o aún que es el fruto del

61 Acerca de esto, es interesante señalar la creación de "nuevos imaginarios geográficos", desde una estética asociada a los bosques encantados, las hadas y los seres mágicos provenientes del folclore europeo, entremezclados con elementos de la cultura local, principalmente mapuche. Esta nueva forma de reconstrucción de la mitología local se plasma en la confección de muñecos de fieltro, madera y lana que forman parte de los "Talleres de Seres Mágicos" que impulsa la Fundación de Huilo-Huilo, y que agrupa alrededor de 45 personas.

62 Leff, 2006.

63 De un modo general, las mujeres tienen una apreciación positiva de estos talleres, dado que les han otorgado más autonomía y permitido mejorar la renta familiar. No obstante, no se puede ignorar que esas actividades acaban por promover una "cultura emprendedora", que busca hacer con que los (las) campesino(a)s pasen a actuar según la racionalidad moderno-capitalista, en detrimento de los marcos de referencia y de las pautas de raciocinio que les son peculiares. 64 A partir de las informaciones que han sido levantadas en terreno, se estima que gran parte de los habitantes de Neltume trabaja hoy en los hoteles y en los demás negocios de turismo manejados por el grupo Themcorp. Respecto a la calidad del trabajo, los relatos son contradictorios, mientras que unos afirman la importancia de Huilo Huilo para la generación de empleo, otros informan de ciertas disconformidades en lo que se refiere a los bajos sueldos, a la superexplotación de la mano de obra y a las dificultades en sindicalizarse.

65 Alfaro Moonsalve, 2016. 
"amor" de los principales accionistas del grupo por aquel lugar. Aunque no descartamos que estos motivos puedan haber influido en la conformación de la reserva y al desarrollo de negocios "sustentables", pensamos que los cambios en el modo de acción empresarial en la zona se dieron por otras razones, mucho más pragmáticas. Como fue examinado más arriba, bajo las condiciones producidas por el neoliberalismo y la urbanización, pasa a ser mucho más ventajoso extraer renta de la tierra por medio de los negocios de la conservación, que simplemente tallando el bosque.

Aprovechándose del derecho de monopolio garantizado por la propiedad privada de la tierra, y valiéndose de la valoración de las propiedades estéticas y ecológicas (únicas y no reproducibles) de la zona andino-lacustre de Los Ríos, el grupo Themcorp paulatinamente fue dejando de invertir solamente en la explotación maderera, para adentrarse cada vez más en el ramo de la conservación ambiental y del turismo que, a partir de principios de los años 2000, se convirtió en la principal forma de acción del grupo en la zona ${ }^{66}$. En este sentido, actualmente el grupo no sólo posee la Reserva Huilo Huilo, como también las concesiones de la administración de la Reserva Mocho-Choshuenco ${ }^{67}$ y del embarcadero Hua Hum en Puerto Fuy que liga Chile a Argentina.

Buscando extraer lo máximo de ganancias por medio de las ventajas naturales que han monopolizado en la zona, el holding ha invertido pesadamente en potencializar las formas de ocio y de consumo del espacio, dando lugar a un espectacular complejo turístico-hotelero que cuenta con los más diversos tipos de alojamientos, desde un camping y un refugio para backpackers, hasta lujosos lodges y espectaculares y hoteles, como el Hotel Montaña Mágica, en formato de volcán, el cual es cubierto por una majestuosa cascada (ver figura 02), sumados a cafés, restaurantes, cervecería artesanal y un museo.

Por medio del turismo, la conservación ambiental no solo es mercantilizada, sino que se transforma en espectáculo, "un producto que conjuga el paisaje, el cuidado de los recursos naturales, la belleza escénica, la fauna y que, en forma paralela, concibe la hotelería y el glamour del turismo"68. Asimismo, la empresa posee aún un emprendimiento inmobiliario denominado Loteo Bosque Quebrada Honda, con parcelas de agrado "sostenibles", destinadas aquellas personas que pretenden "vivir la magia de nuestra naturaleza" 69 . Tal como recuerda Harvey (1990), los capitalistas pueden acceder a ganancias extraordinarias, cuando poseen en sus manos determinados valores de uso de calidad superior. En este caso específico, los "valores de

66 No obstante, es de fundamental importancia dejar claro que el grupo Themcorp sigue actuando en la zona con la explotación maderera y forestal, a través de la Forestal Neltume Carranco S.A. Se trata, por lo tanto, de la monopolización del lugar, a través del control casi que absoluto sobre todas las actividades económicas realizadas allá.

67 La Reserva Nacional Mocho-Choshuenco fue creada en marzo de 1994 por Decreto Supremo $\mathrm{N}^{\circ} 55$ del Ministerio de Agricultura. En 2011, por medio de una asociación público-privada, la administración de la Reserva paso a ser de responsabilidad de la fundación Huilo Huilo.

68 ANDRADE, 2002.

69 Fuente: $<w w w . v i v i r e l b o s q u e . c l \geq[10$ de abril de 2016] 
uso de calidad superior" se relacionan con aquello que comúnmente es considerado "bonito" y/o "rico"70.

También es necesario tener en consideración otro aspecto crucial que ha motivado la nueva estrategia de acción del grupo empresarial en la zona, que tiene que ver justamente con una eficiente operación de greenwashing, cuyo objetivo es mejorar su imagen institucional. En tiempos ultra-competitivos, tener una buena percepción pública se transforma en una importante ventaja en la lucha por mantenerse vivo en el juego capitalista. Gracias a sus acciones de "sustentabilidad" y de

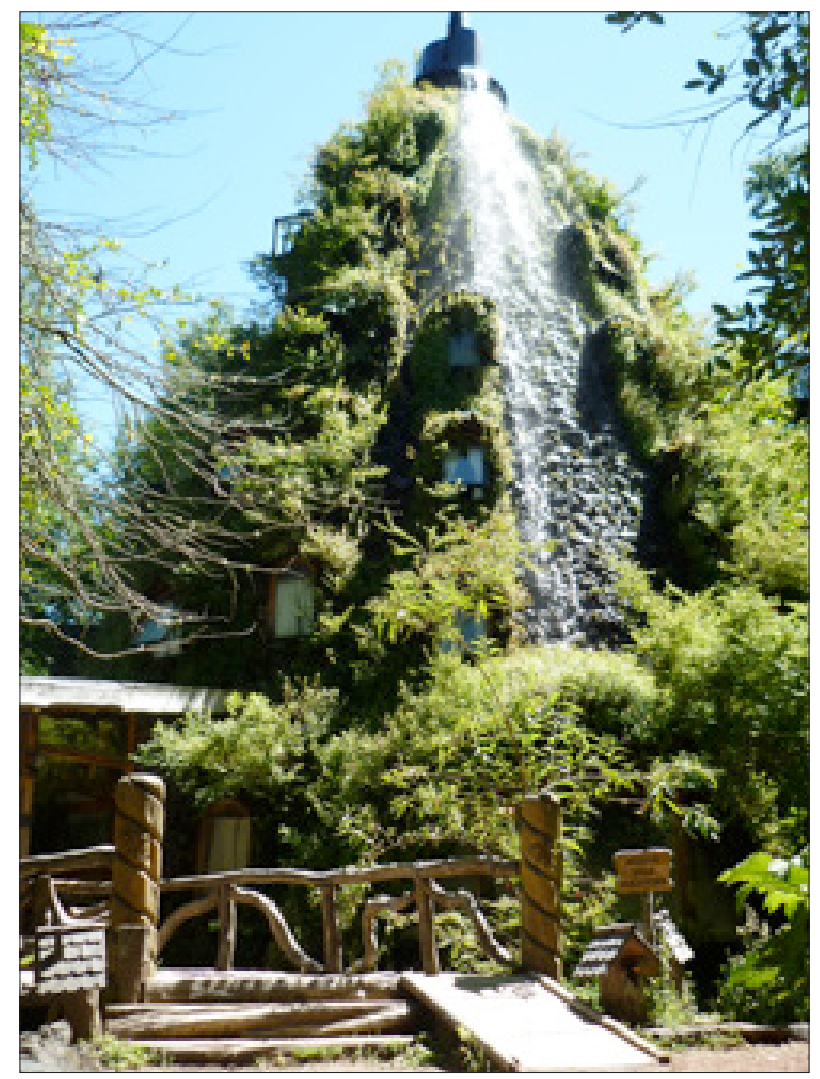

Figura 02: Detalle del hotel Montaña Mágica, espectacular construcción que parece haber salido de una película de Star Wars. Para hospedarse en el hotel, el huésped debe pagar una diaria mínima de 187 dólares, en temporada baja.

Fuente: archivo personal.

"responsabilidad empresarial", Huilo Huilo ha sido galardonada en 2015 con el premio World Legacy, otorgado por la National Geographic Society, en la categoría "Conservación del Mundo Natural". Esto, junto con los numerosos reportajes sobre la reserva, ha contribuido para desvincular Huilo Huilo de los otros negocios del holding, generando una imagen positiva que enmascara los conflictos socioambientales en

70 Estas apreciaciones son en última instancia ideológicas y socialmente construidas. En este sentido, este tipo de conservación aún trae consigo otro peligro, que es justamente priorizar determinados ecosistemas en detrimento de otros. Es decir, no se valora igualmente un pantano, o a una vegetación del secano, en comparación con los bosques húmedos y los lagos, aunque todos ellos sean importantes en términos ecológicos. 
los cuales Themcorp está involucrado (directa o indirectamente) ${ }^{71}$, incluyendo, evidentemente, las contradicciones vinculadas a la configuración y al funcionamiento de la reserva.

Ahora bien, aunque las acciones de comunicación y marketing sean hábiles y potentes, ellas no logran esconder por completo las contradicciones vinculadas a la territorialización del ambientalismo de raíz empresarial ${ }^{72}$. Entre esos aspectos contradictorios, podemos destacar inicialmente la imposición de un conservadorismo restrictivo y exógeno, que además de privatizar la naturaleza y transformarla en mercancía, reproduce la vieja dicotomía que ha dominado el pensamiento conservacionista occidental desde el siglo XIX (esto puede ser percibido, entre otras cosas, en la prohibición de la recolección de los productos del bosque y la negación del libre acceso a lugares y caminos antes públicos). Más aun, este tipo de discurso-práctica, al reforzar la ideología liberal acaba, de cierta manera, obliterando ${ }^{73}$ otras formas de producir el espacio, organizarse en sociedad y pensar la relación entre los seres humanos y el mundo natural. Sobre todo aquellas que fueron construidas a lo largo de generaciones, particularmente por el pueblo mapuche. Así, la territorialización de este tipo de conservación ambiental -basado no solo en un "mito moderno de una naturaleza intocada"74, sino que orientado por la lógica del mercado y de la propiedad privada- tiende a generar una serie de impactos sobre la reproducción del modo de vida y de la cotidianeidad de los trabajadores, de los campesinos y de las poblaciones originarias, que merecen ser mejor exploradas.

Asimismo, la siempre delicada relación que se establece entre la conservación ambiental y la reproducción capitalista acaba por tensionar las diferentes maneras de pensar la naturaleza y producir el espacio territorializados dialécticamente en la zona. En este sentido, los conflictos socioambientales tienden a ser complejizados, como revelan los recientes embates entre organizaciones ambientalistas y comunidades mapuche de Neltume y Puerto Fuy, y el empresario Victor Petermann, princi-

71 Es el caso de la Mina Panales, faena minera operada por la Minera Esparta, empresa que es acusada de haber extraído cobre de forma ilegal en la Quebrada de la Plata, ocasionando diversos daños a un importante remaneciente del bosque esclerófilo característico de la zona central chilena en la Región Metropolitana. De acuerdo con reportaje del Centro de Investigaciones Periodísticas (CIPER), “aunque el sector es considerado en el Plan Regulador Metropolitano de Santiago (PRMS) como zona de preservación ecológica, Minera Esparta lo convirtió en una mina a rajo abierto que ha pasado por encima de todas las regulaciones mineras y medioambientales del país. Y de paso, ha demostrado las limitantes institucionales para detener las faenas que operan al margen de la ley". A pesar de que la empresa responsable por las faenas -la Minera Esparta- es de propiedad de Branko Donoso, es importante señalar que este es apenas un arrendatario de la mina Panales, que pertenece a una sociedad del grupo Tehmcorp. Fuente: Centro de Investigación Periodística (CIPER) <http://ciperchile.cl/2015/04/06/mineria-ilegal-enmaipu-la-destruccion-de-la-quebrada-de-la-plata>. [15 de marzo de 2017].

72 Por ahora, nos limitamos apenas a señalar esas contradicciones y conflictos que serán blanco de un análisis más detallado en otros trabajos.

73 En realidad, no se trata propiamente de "obliterar", sino que de incorporar otros modos de vida, cosmovisiones y formas de producir el espacio y la naturaleza, circunscribiéndolos a la lógica del capital.

74 Diegues, 1994. 
pal controlador del grupo Themcorp. Esto en función de la construcción de centrales hidroeléctricas de paso bajo su responsabilidad (incluyendo una central al interior de la reserva Huilo Huilo), y de su apoyo al proyecto hidroeléctrico Central Neltume, para el cual arrienda parte de un terreno de su propiedad en Remeco, que es utilizado como la galería de prospección de esas obras ${ }^{75}$.

Finalmente, no debemos ignorar los peligros involucrados con la "apropiación monopólica" del lugar, representada no solo por el acaparamiento de tierras, sino que también por la concentración de parte considerable de los negocios desarrollados en la zona. De igual manera, precisamos tener en consideración el componente ideológico de este proceso, caracterizado por la reproducción de un discurso de base "común" (que cuenta con la valiosa ayuda de los medios de comunicación y del poder público), que vincula el bienestar de las comunidades locales y la protección del bosque húmedo templado a las necesidades y ansias de la empresa-reserva. A partir de la idea de que "lo que es bueno para la empresa, es bueno para todos", se crea la sensación que no es posible que existan otras alternativas de conservación ambiental y de reproducción social más allá de los límites del capital.

\section{Consideraciones Finales}

A lo largo de las últimas tres décadas, el medio rural de la zona andino-lacustre de la región de Los Ríos viene experimentando un proceso de profunda resignificación engendrado, en gran medida, por la valoración de la naturaleza y del paisaje. Hasta la década de 1980, la talla del bosque y/o la expansión de los cultivos forestales representaban las actividades económicas dominantes en la zona, y la producción de aquel espacio se hacía en conformidad con las necesidades de la industria maderera-forestal. Recientemente, con la crisis ambiental y la flexibilización de la economía capitalista, los lugares cordilleranos cubiertos por el bosque valdiviano pasaron a ser cada vez más valorados en función de su potencial ecológico y paisajístico.

Bajo este contexto, el medio rural de la zona andino-lacustre de la región de Los Ríos se ha convertido en una nueva frontera para la expansión capitalista, ahora sustentada por la ideología de una naturaleza prístina. Así, la conservación ambiental se ha transformado en un lucrativo negocio, y los negocios de la conservación vienen cumpliendo un papel cada vez más determinante en la producción capitalista de aquel espacio. Entre los nuevos negocios que se han territorializado en la zona, las reservas privadas de conservación ambiental se destacan, actuando como un potente catalizador para la transformación socioespacial local, vinculada al proceso más amplio de comodificación de la naturaleza y del paisaje. Como consecuencia, nuevos conflictos y contradicciones son verificados, particularmente en lo que dice respecto a la apropiación privada de los bienes comunes, al incremento de la especulación inmobiliaria y a la re-concentración fundiaria.

75 Fuente: El Puelche. http://www.elpuelche.cl/2015/07/03/panguipulli-las-conversaciones-delas-comunidades-con-victor-petermann/. [10 de abril de 2016] 
Conforme hemos visto, la reserva biológica Huilo Huilo, vinculada al grupo económico Themcorp, constituye uno de los casos más representativos de cómo el discurso y las prácticas "conservacionistas" se han convertido en una nueva estrategia de acumulación capitalista en la zona. Sin embargo, su ejemplo ha sido reproducido en otros lugares, como es el caso del Parque Futangue, ubicado en la localidad de Riñinahue, comuna del lago Ranco. Con 13.500 hectáreas el parque pertenece a la fundación Ranco, de propiedad de un destacado empresario y político nacional ${ }^{76}$. A pesar de las posibles diferencias de escala y de infraestructura, la conformación y el funcionamiento de esos proyectos de conservación de raíz empresarial, obedecen más o menos a una misma lógica, además de estimular la territorialización de nuevas actividades, negocios y dinámicas socioespaciales. Al final, como recuerda Cindy Katz (1998), bajo el alero del capital, los proyectos de conservación ambiental ligados al medio empresarial son mucho más que simples reservas de biodiversidad. Estos sitios son, en verdad, espacios productivos (o potencialmente productivos), creados y reproducidos según las necesidades actuales de la acumulación. Es por este motivo que, en esos tiempos neoliberales, la conservación ambiental y la privatización pasaron a estar mutuamente implicadas.

Finalmente cabe señalar que el proceso de comodificación de la naturaleza y del paisaje de la zona andino-lacustre de Los Ríos es demasiado amplio y complejo, y en esta instancia solo fue posible señalar de modo inicial y breve algunas de sus múltiples aristas, específicamente aquellas vinculadas a la configuración de la reserva Huilo Huilo. De este modo, diversas otras cuestiones aún permanecen abiertas y/o poco explicadas, haciendo necesario resolverlas en la medida que avancemos con nuestra investigación. Con esto, esperamos contribuir a la composición de un panorama más completo de lo que está sucediendo hoy en el medio rural de sur de Chile, ayudando a explicitar las nuevas estrategias de uso y de apropiación de la tierra vinculadas a la transformación de la naturaleza conservada y del paisaje en mercancías, así como las contradicciones socioespaciales engendradas por este proceso.

\section{Bibliografía}

ALESSANDRI CARLOS, Ana Fani. "Novas" contradições do espaço. In: DAMIANI, Amélia Luisa; ALESSANDRI CARLOS, Ana Fani; CARVALHO DE LIMA SEABRA, Odette (orgs.). O espaço no fim do século: a nova raridade. São Paulo: Contexto, 2001, p.62-74.

ALFREDO, Anselmo. A geografía do turismo: a crise ecológica como critica objetiva do trabalho (o turismo como ilusão necessária). Revista Geousp, 2001, nº 09, p. 37-62.

ALFARO MONSALVE, Karen. Acumulación por desposesión en Chile: el caso del Complejo Forestal y Maderero Panguipulli en sur de Chile (1973-1990). Revista Historia 396, 2016, nº 02, p.229-255.

76 Se trata de Gabriel Ruiz-Tagle, vinculado al partido de derecha Unión Demócrata Independiente (UDI) y que actuó como subsecretario y posteriormente como Ministro de Deportes del gobierno de Sebastián Pinera. 
ANDRADE, Pedro. Reserva Huilo-Huilo: Un ejemplo de nuevo paradigma en la integración del bosque nativo al manejo productivo de recursos naturales y ecoturismo. Revista Bosque Nativo, 2002, no 50, <http://revista.bosquenativo.cl/ volumenes/50/2_repor.htm>. [06 de abril de 2016].

BARRENA RUIZ, José; HERNANDO ARRESE, Maite; ROSAS MARCHINI, Fernanda. Antecedentes históricos sobre el Complejo Historico Maderero Panguipulli, província de Valdívia, centro-sur de Chile. Revista Bosque, 2016, nº 37, p.473-484.

BLANCO WELLS, Gustavo. La reinvención de la Patagonia: Gente, mitos, mercancías y la continua apropiación del territorio. In: ELLISON, Nicolas; MARTINÉZ MAURI, Monica (Coords.). Paisaje, espacio y territorio: reelaboraciones simbolicas y reconstrucciones identitárias en America Latina.Quito - Ecuador: Abya Ayala, 2009, p. 89-108.

CATALÁN, Rodrigo; WILKEN, Petra; KANDZIOR, Angelika; TECKLIN, David.; BURSCHEL, Heinrich (eds). Bosques y comunidades del sur de Chile. Santiago de Chile: Editora universitaria, 2005, 359p.

COMITÉ MEMORIA NELTUME. Guerrilla en Neltume:una historia de lucha y resistencia en el sur de Chile. Santiago de Chile: LOM, 2013, 315p.

COMISION VERDAD HISTÓRICA Y NUEVO TRATO CON LOS PUEBLOS INDÍGENAS. Informe de la Comision Verdad Historica y Nuevo Trato con los Pueblos Indigenas. Santiago de Chile: Comisionado Presidencial para Asuntos Indígenas, 2008, $683 p$.

DE MATHEUS E SILVA, Luis Fernando. Ilusão concreta, Utopia possível: Contraculturas Espaciais e Permacultura (uma mirada desde o cone sul). Tesis doctoral dirigida por Marta Inez Medeiros Marques. São Paulo: Faculdade de Filosofia, Letras e Ciências Humanas, Universidade de São Paulo, 2013.336p.

DE MATHEUS E SILVA, Luis Fernando. Desposeer para acumular: reflexiones sobre las contradicciones del proceso de modernización neoliberal de la agricultura chilena. Revista Mundo Agrario. vol. 17, n 34, 2016.

DIEGUES, Antonio Carlos. O mito moderno da natureza intocada. São Paulo: Hucitec, 1994, 163 p.

ECHENIQUE, Jorge. El caso de Chile. In: SOTO BAQUERO, Fernando; GÓMEZ, Sergio (eds.). Dinámicas del Mercado de la Tierra en América Latina y el Caribe. Santiago: FAO, 2012, p. 145-178.

GÁRATE CHATEAU, Manuel. La revolución capitalista de Chile (1973-2003). Santiago de Chile: Ediciones Alberto Hurtado, 2012, 589p.

HARVEY, David. Los limites del capitalismo y la teoría marxista. D.F. Mexico: FCE, 1990, $469 p$.

HARVEY, David. El nuevo imperialismo Madrid: Akal, 2004, 170p.

HARVEY, David. Espacios del capital. Madrid: Akal, 2009, 445p.

KATZ, Cindy. Whose nature, whose culture? (prívate productions of space and the "preservation" of nature). En: BRAUN, Bruce; CASTREE, Noel (eds.). Remaking Reality. London; New York: Routledge, 1998, p.46-63. 
LEFEBVRE, E. A Revolução Urbana. Belo Horizonte: UFMG, 2004, 178p.

LEFF, Enrique. Racionalidade ambiental: A reapropriação social da natureza. Rio de Janeiro: Civilização brasileira, 2009, 555p.

MARX, Karl. O Capital - livro I. São Paulo: Boitempo, 2013, 894p.

MINISTERIO DEL MEDIO AMBIENTE CHILE. Las áreas protegidas de Chile. <http:// Www.mma.gob.cl/1304/articles-50613_pdf.pdf>.[ 25 de febrero de 2016].

MOREIRA, Roberto José. Renda da natureza e territorialização do capital: reinterpretando a renda da terra na competição intercapitalista. Revista Estudos Sociedade e Agricultura, nº 04, 1995, pp. 89-111.

NUÑEZ, Andrés; ALISTE, Enrique. BELLO, Álvaro. Patagonia-Aysén en la construcción del imaginario geográfico de la nación. Iztapalapa Revista de Ciencias Sociales y Humanidades, $\mathrm{n}^{\circ}$ 76, año 35, 2014, p. 165-188.

NUÑEZ, Andrés; ALISTE, Enrique. BELLO, El discurso del desarrollo en la PatagoniaAysén: la conservación y la protección de la naturaleza como dispositivos de una renovada colonización. Chile, siglos XX-XXI. In: XIII Coloquio Internacional de Geocritica, 2014a. <http://www.ub.edu/geocrit/coloquio2014/Andres\%20 Nunez.pdf $>$.[06 de abril de 2016]

PAUCHARD, Aníbal; VILLAROEL, Pablo. Protected areas in Chile. History, Current state and Challenges. Natural Areas Journal, vol. 17, nº 4, p. 318-330.

PORTO-GONÇALVES, Carlos Walter. A globalização da natureza e a natureza da globalização. Rio de Janeiro: Civilização Brasileira, 2006, 46l p.

RIVERA, Claudio; VALLEJOS-ROMERO, Arturo. La privatización de la conservación en Chile: repensando la gobernanza ambiental. Revista Bosque, 2015, nº 36, p. 15-25.

SMITH, Neil Neil. Uneven Development. London; New York: Verso, 2010, 323p.

SKEWES, Juan Carlos; GUERRA, Debbie; ROJAS, Pablo; MELLADO, Maria Amalia. ¿La memoria de los paisajes o los paisajes de la memoria? Los enigmas de la sustentabilidad socioambiental en las geografías en disputa. Revista Desenvolvimento e Meio Ambiente, 2011, n. 23, pp.39-57.

OLIVEIRA, Ariovaldo. Modo capitalista de produção, agricultura e reforma agrária. [En línea]. São Paulo: FFLCH-USP, 2007, 184 p. <http://gesp.fflch.usp.br/sites/gesp. fflch.usp.br/files/modo_capitalista.pdf>. [23 de enero de 2016]. ISBN: 978-857506-145-9.

(c) Copyright: Luis Fernando de Matheus e Silva; Hugo Marcelo Zunino; Viviana Huiliñir Curío, 2018

(c) Copyright Scripta Nova, 2018.

Ficha bibliográfica:

DE MATHEUS e SILVA; Luis Fernando; ZUNINO, Hugo Marcelo; UILIÑIR CURÍO, Viviana. El negocio de la conservación ambiental: cómo la naturaleza se ha convertido en una nueva estrategia de acumulación capitalista en la zona andino-lacustre de Los Ríos, sur de Chile Scripta Nova. Revista Electrónica de Geografía y Ciencias Sociales. [En línea]. Barcelona: Universidad de Barcelona, 1 de febrero de 2018, vol. XXII, $\mathrm{n}^{\circ}$ 583. ISSN: 1138-9788. 